\title{
Anterior Choroidal Artery Territory Stroke in Young Patient
}

\author{
Denise Lopes $^{1}$, Helena Felgueiras ${ }^{2}$, Pedro Carneiro ${ }^{2}$ \\ ${ }^{1}$ Internal Medicine Service, Hospital Pedro Hispano, Matosinhos, Portugal \\ ${ }^{2}$ Neurology Service, Hospital Santos Silva, Vila Nova de Gaia, Portugal \\ Email: ana.denise.lopes@gmail.com
}

Received 31 June 2014; revised 25 July 2014; accepted 18 August 2014

Copyright @ 2014 by authors and Scientific Research Publishing Inc.

This work is licensed under the Creative Commons Attribution International License (CC BY).

http://creativecommons.org/licenses/by/4.0/

(c) (i) Open Access

\section{Abstract}

Introduction: Stroke incidence in young patients is about 10 cases in 100.000 , according to several European studies. In this age group arterial dissection is one of the main pathological mechanisms involved. The internal carotid's artery (ICA) main supraclinoid branch is the anterior choroidal artery (AChA). The occurrence of infarction in its territory due to internal carotid dissection is considered to be a rare event and may have different clinical presentations due to anatomical variability. Clinical case: A 31-year-old male patient, without any known cardiovascular risk factors or chronic medication, presented with acute onset of stabbing right sided headache while practicing football. Visual disturbances and hemiparesis with hypesthesia of his left arm were also mentioned. On admission left homonymous hemianopsia, left hemiparesis and left extensor plantar reflex were present. Brain magnetic resonance showed hyperintensity of T2 and FLAIR signals and restricted diffusion pattern suggested acute/subacute infarctions in the thalamic and subcapsular area, corpus callosum, splenium and subcortical parietal right region. Magnetic resonance angiography (MRA) of the brain showed reduction of the right ICA's caliber, mainly of its supraclinoid segment in which a marked irregular stenosis was visualized, suggestive of arterial dissection. This stenotic segment included the origin of the AChA and of the posterior communicating cerebral artery with an exchange in their territories. Lumbar puncture results were normal as were analytical investigations which included $C B C$, sedimentation rate, syphilis serology and immunologic and prothrombotic screen. There were no phenotype characteristics suggestive of connective tissue disease. Conclusion: Trauma seems to be the most probable lesion mechanism for the occurrence of intracranial carotid's dissection in this particular case, as the patient was practicing vigorous sports at time of onset. In view of great anatomic variability and multiple anatomical sites supplied by the AChA its occlusion will induce a wide range of clinical manifestations. 


\section{Keywords}

\section{Anterior Choroidal Artery, Stroke, Dissection, Young Patient}

\section{Introduction}

The anterior choroidal artery (AChA) is the main branch of the supraclinoid segment of the internal carotid artery (ICA). It originates from the posterior wall of the ICA, 2 - $5 \mathrm{~mm}$ distally to the posterior communicating artery (PComA) and can be divided into two segments cisternal and intraventricular. On its course it supplies important sensory and motor structures such as the uncus, lateral portion of the geniculate body, posterior limb of the internal capsule, optic radiation and the choroid plexus of the lateral ventricle [1]. Anatomical variation is frequent and territory interchangeability can occur with the PComA and (perforating) branches arising from de middle cerebral artery (MCA) namely in the internal capsule supply. The cerebral peduncle, substantia nigra, optic tract and lateral geniculate body can also be supplied by branches of posterior cerebral artery [1]. This variability accounts for the unpredictability of the consequences of AChA occlusion.

There is little literature exclusively on AChA stroke, but its prevalence ranges from $2.5 \%$ to $11 \%$ [2]. It is frequently considered as a type of lacunar infarction according to the TOAST classification [3] [4], but large vessel disease, cardioembolic or other causes can also be responsible for stroke occurrence [2]-[4].

In 1925 Foix et al. [5] described the full clinical picture associated with AChA territory infarction which included hemiparesis, hemianesthesia and hemianopia. The motor deficit is the most common manifestation, present in $87 \%$ to $100 \%$ of patients and it's caused by the interruption of corticospinal tract fibers which descend in the posterior limb of the internal capsule and the cerebral peduncle [2]. The sensory deficit was variable with reported rates between $33 \%$ and $81 \%$ in the literature [2]. Homonymous hemianopia best correlated with lesions within the posterior limb and the retrolenticular portion of the internal capsule [6] and visual disturbances were present between $0 \%$ and $42 \%$, often transiently due to collateral circulation.

Ischemic stroke incidence in the young has been on the rise in recent years, probably associated with an increase of vascular risk factors. Extracranial cervical dissection accounts for nearly $20 \%$ of ischemic stroke in younger patients [7] and the internal carotid artery is one of the main sites concerned, second only to the vertebral arteries. Dissections of the carotid artery can occur either intra or extracranially, being more frequent in the latter. Main causes are major or minor trauma [7] but dissections can happen spontaneously particularly in patients with connective tissue diseases or other genetic, familial and heritable disorders.

\section{Case Report}

A 31-year-old male patient working as a gymnastic's instructor, was admitted to the Neurology Division of this hospital. His past medical history was significant only for previous diagnosis of Gilbert's syndrome and family history was non contributory. He also denied any toxic ingestion. He presented with a sudden onset of stabbing right sided headache while he was playing football. Almost simultaneously he suffered visual disturbances specially in his left eye, which impaired his perception of space and distance. Posteriorly he developed hemianesthesia and hemiparesis in his left arm that persisted for at least 24 hours before coming to the emergency service.

On admission left homonymous hemianopia, left hemiparesis scoring $4+/ 5$ on motor scale grading, and left extensor plantar reflex were present. Visual acuity assessment was 8/10 on the left eye, 10/10 on the right eye. Physical examination showed no phenotype characteristics suggestive of connective tissue disease.

A computed tomography angiography (CTA) scan of the brain showed no alterations namely aneurisms. However, Brain MRI showed hyperintense T2* FLAIR signal and restricted diffusion pattern that suggested acute/subacute infarctions in the talamo-capsular area, corpus callosum splenium and subcortical parietal right region. Magnetic resonance angiography (MRA) of the brain revealed a reduction of the right ICA's caliber, starting in its petrous portion but mainly of its supraclinoid segment in which a marked irregular stenosis was visualized. This stenotic segment included the origin of the AChA and PComA. There seemed to be an exchange of their territories since the AChA possessed a large caliber extending to the occipital lobe and the PComA penetrated the choroidal fissure.

Lumbar puncture was performed showing normal characteristics, total protein content in the reference range 
and no red or white cels. CBC and sedimentation rate were within normal values and syphilis, viral hepatitis and HIV serologies were negative. Immunologic and prothrombotic screen which included antinuclear and antineutrophil cytoplasm antibodies, angiotensin converting enzyme, lupus anticoagulant, B2 glycoprotein and anticardiolipin antibodies, prothrombin time and activated partial thromboplastin time as well as homocystein levels and $\mathrm{C}$ and $\mathrm{S}$ protein assessment all with normal results.

Antiplatelet drug therapy was initiated and there was a complete resolution of neurological deficits. Repetition of brain MRA showed reperfusion of the affected vessels and the patient was discharged to further follow-up at Neurological consultation. Six months after this event he remained asymptomatic.

\section{Discussion}

This patient presented with a sudden and intense headache accompanied by neurological deficits. The main diagnostic hypothesis initially considered was ruptured aneurism and subarachnoid hemorrhage. When initial exams excluded hemorrhagic stroke, the possibility of ischemic stroke grew stronger. In a young patient without cardiovascular risk factors or significant family history, arterial dissection seemed probable. Dissection of ICA occurs frequently, mainly in its extracranial segment. Intracranial ICA dissection causing AChA stroke is considered a rare event. However Leys et al. [3] reported two cases of AchA stroke due to ICA dissection in a small group of only 16 patients in 1994. Posteriorly in a review [7] of ischemic stroke in 287 young patients by the same author a single case of intracranial ICA dissection was found. In a more recent review from South Korea [8] in a total of 128 patients with presumed AChA infarction enrolled during a ten-year period only a single case of arterial dissection was reported.

Trauma seems the most likely lesion mechanism for the occurrence of carotid's branch dissection in this particular case, as the patient was practicing vigorous sports at time of onset. There was no recent history of infection nor drug use, more commonly associated with spontaneous arterial dissection. Additionally phenotypical changes were absent on physical examination and homocysteine levels were normal.

\section{Conclusions}

In view of great anatomic variability and territory interchangeability of the AchA, its occlusion can induce a wide range of clinical manifestations. Our patient presented with a acute headache and discrete motor and sensory deficit and valued mainly visual disturbances which are not very typical of AchA infarction. Additionally MRA showed some variation of AChA and PComA caliber and course.

The evolution of this case was a highly favorable one, with complete resolution of clinical manifestations.

\section{References}

[1] Baskaya, M.K., Coscarella, E., Gomez, F. and Morcos, J.J. (2004) Surgical and Angiographic Anatomy of the Posterior Communicating and Anterior Choroidal Arteries. Neuroanatomy, 3, 38-42.

[2] Pezzella, F.R. and Vadalá, R. (2012) Anterior Choroidal Artery Territory Infarction. Frontiers of Neurology and Neuroscience, 30, 123-127. http://dx.doi.org/10.1159/000333608

[3] Leys, D., Mounier-Vehier, F., Lavenu, I., Rondepierre, P. and Pruvo, J.P. (1994) Anterior Choroidal Artery Territory Infarcts. Study of Presumed Mechanisms. Stroke, 25, 837-842. http://dx.doi.org/10.1161/01.STR.25.4.837

[4] Ois, A., Cuadrado-Godia, E., Solano, A., Perich-Alsina, X. and Roquer, J. (2009) Acute Ischemic Stroke in Anterior Choroidal Artery Territory. Journal of the Neurological Sciences, 281, 80-84. http://dx.doi.org/10.1016/j.jns.2009.02.323

[5] Foix, C., Chavany, J., Hillemand, P. and Shiff-Wertheimer (1925) Oblitération de l'artére choroidienne antérieure: Ramolissement de son territoire cerebral: Hémiplégie, hémianesthésie, hémianopsie. Bulletim Ophtalmol Paris, 37, 221-223.

[6] Hupperts, R.M., Lodder, J., Heuts-van Raak, E.P. and Kessels, F. (1994) Infarcts in the Anterior Choroidal Artery Territory. Anatomical Distribution, Clinical Syndromes, Presumed Pathogenesis and Early Outcome. Brain, 117, 825834. http://dx.doi.org/10.1093/brain/117.4.825

[7] Leys, D., Bandu, L., Hénon, H., Lucas, C., Mounier-Vehier, F., Rondepierre, P. and Godefroy, O. (2002) Clinical Outcome in 287 Consecutive Young Adults (15 to 45 Years) with Ischemic Stroke. Neurology, 59, 26-33. http://dx.doi.org/10.1212/WNL.59.1.26

[8] Sohn, H., Kang, D.-W., Kwon, S.U. and Kim, J.S. (2013) Anterior Choroidal Artery Territory Infarction: Lesions Confined to versus beyond the Internal Capsule. Cerebrovascular Diseases, 35, 228-234. http://dx.doi.org/10.1159/000347069 
Scientific Research Publishing (SCIRP) is one of the largest Open Access journal publishers. It is currently publishing more than 200 open access, online, peer-reviewed journals covering a wide range of academic disciplines. SCIRP serves the worldwide academic communities and contributes to the progress and application of science with its publication.

Other selected journals from SCIRP are listed as below. Submit your manuscript to us via either submit@scirp.org or Online Submission Portal.
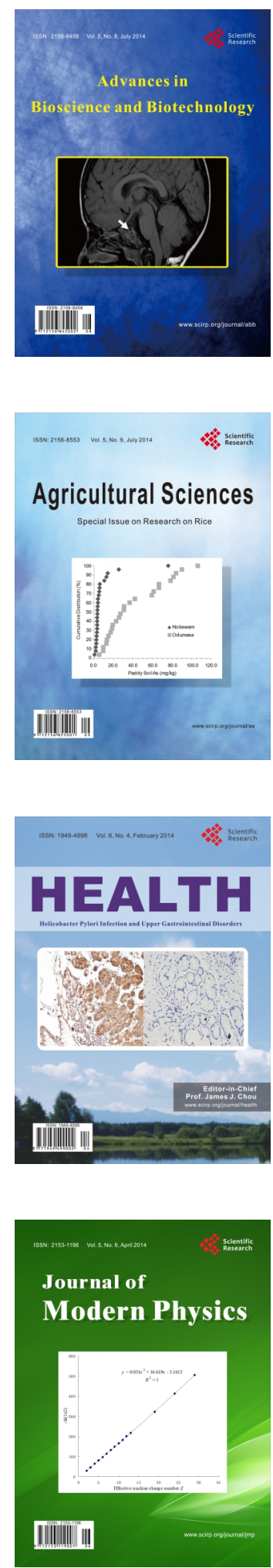
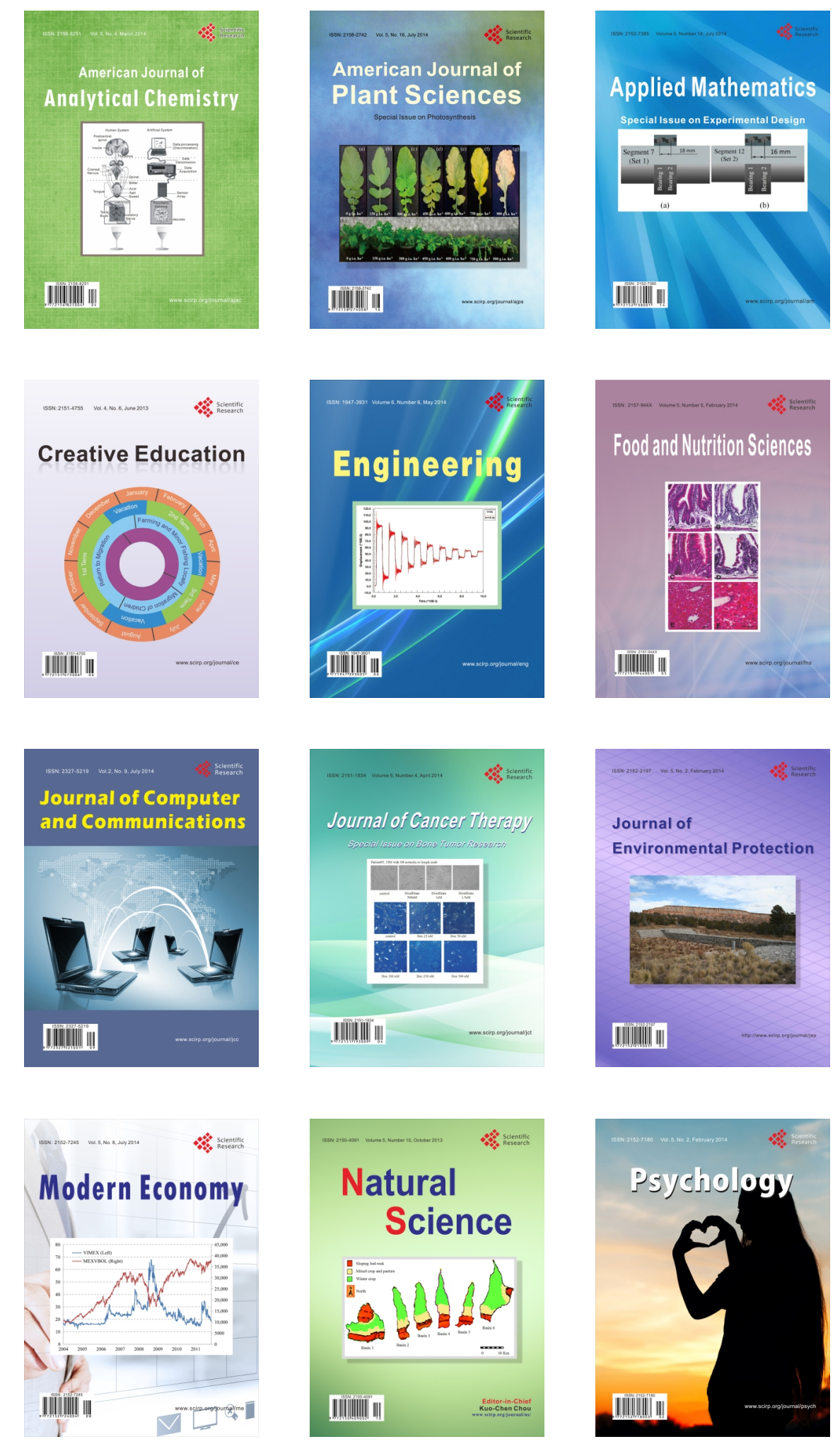